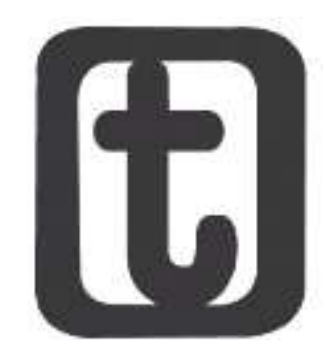

\title{
DIRETRIZES CURRICULARES DA ABEPSS E A QUESTÃO AGRÁRIA
}

\author{
ABEPSS's Curricular Guidelines and Agrarian Question
}

\author{
Raquel Santos Sant' Ana*
}

\begin{abstract}
RESUMO
Este artigo traz o debate da questão agrária como uma particularidade da questão social e a partir desse entendimento constrói o diálogo com o projeto de formação do serviço social brasileiro. Parte-se do pressuposto que as Diretrizes Curriculares da Associação Brasileira de Ensino e Pesquisa em Serviço Social (ABEPSS), que tem como fundamento a teoria social de Marx, exige a apreensão dos diversos conteúdos numa perspectiva de totalidade e, portanto, permite a análise das particularidades da questão agrária nos diferentes conteúdos dos núcleos que estruturam a proposta formativa. No entanto, a dificuldade na apropriação desse referencial e a perspectiva urbanocêntrica e fragmentária da produção do conhecimento pode afetar essa apreensão. Este artigo é um exercício de reflexão do lugar da questão agrária como particularidade da questão social em dois núcleos da formação que compõem as diretrizes: o de formação do ser social e o das particularidades da sociedade brasileira, afunilando o debate para uma matéria de maneira a dar visibilidade concreta, ainda que limitada, ao debate da questão agrária no projeto de formação.
\end{abstract}

PALAVRAS CHAVES: Serviço social; Formação profissional; Questão agrária; Questão social; Diretrizes curriculares.

\section{ABSTRACT}

This paper debates the agrarian question as a particularity derived from the so-called social question in order to put it into a dialogue with Brazilian Social Work's curricular project. The paper presupposes that the curricular guidelines of Brazilian Association to Instruction and Research in Social Work (ABEPSS), which are based on Marx's social theory, demand the comprehension of various contents according to a totality-based perspective and allow, for that reason, the analysis of agrarian question's particularities in different areas of those curricular guidelines. Nevertheless, the complexity in appropriating that theoretical references and the problems derived from an urbano-centric and fragmentary perspective in knowledge production may affect that possible apprehension of agrarian question. This paper is an exercise of reflection on the place occupied by agrarian question as a particularity of the social question in two areas of Social Work's curricular guidelines: one concerning to social being formation and other to the peculiarities of Brazilian society, both allowing to think about a discipline which increases visibility to the debates on agrarian question in Social Work's curricular guidelines.

\footnotetext{
* Assistente Social. Doutora e Livre docente em Serviço Social. Professora adjunta da Faculdade de Ciências Humanas e Sociais da Universidade Estadual Paulista, Campus de Franca. (UNESP, Franca, Brasil). Av. Eufrásia Monteiro Petráglia, 900, Prolongamento Jardim Dr. Antonio Petraglia, Franca (SP), CEP.: 14409-160. ORC ID: https://orcid.org/0000-0002-2270-5541. E-mail: <raquelssfranca@yahoo.com.br>.
}

\section{DOI 10.22422/temporalis.2019v19n37p172-188} Commons Atribuição 4.0 Internacional (https://creativecommons.org/licenses/by/4.o/deed.pt_BR), que permite copiar e redistribuir o material em qualquer suporte ou formato, bem como adaptar, transformar e criar a partir deste material para qualquer fim, mesmo que comercial. O licenciante não pode revogar estes direitos desde que você respeite os termos da licença. 


\section{KEYWORDS}

Social Work; Professional instruction; Agrarian question; Social question; Curricular guidelines.

\section{INTRODUÇÃO}

$\mathrm{O}$ serviço social brasileiro ao longo dos últimos 40 anos tem feito um esforço teórico e político no sentido de construir uma direção para o trabalho e a formação profissional vinculada a um projeto emancipatório de sociedade, o que pressupõe uma crítica radical ao que Mészáros (2006) chama de ordem sócio metabólica do capital. legado crítico construído pela categoria profissional permite apreender que a questão social, resultado da luta de classes própria das sociedades capitalistas, produz expressões cada vez mais ampliadas das desigualdades sociais cujas manifestações se estendem em âmbito político, econômico e ideopolítico.

Nesse artigo, a partir das Diretrizes Curriculares da Associação Brasileira de Ensino e Pesquisa em Serviço Social (ABEPSS) de 1996, realizamos um ensaio teórico no sentido de contribuir com a apreensão da questão agrária como um componente importante da formação profissional.

A discussão sobre a questão agrária como integrante do complexo analítico que trata daquilo que, no serviço social, se convencionou chamar de questão social deve-se ao entendimento de que o antagonismo das relações entre capital e trabalho se expressa nas atividades produtivas referentes aos diferentes territórios, tanto urbanos quanto rurais. As relações capitalistas se espraiam no âmbito da sociabilidade como um todo; atuam ainda, mediadas por outros componentes, direta ou indiretamente, sobre todas as relações e/ou sistemas cuja lógica ultrapassa as relações de trabalho como é o caso do cerco sobre as terras indígenas e quilombolas, a grilagem, a expulsão das populações camponesas e tradicionais e etc..

A apreensão da questão agrária como particularidade da questão social pode contribuir com o trabalho profissional à medida que fornece mediações mais ampliadas no sentido de entender o embate na relação capital trabalho e suas refrações mais cruéis como as desigualdades no campo, a concentração fundiária, a fome, ao trabalho rural em condições análogas a de escravo e pode, ainda, fornecer subsídios para a análise da questão ambiental e urbana.

No que diz respeito à formação profissional, partimos do pressuposto que o documento da ABEPSS contempla e prevê esse debate, mas que a apreensão da questão agrária como uma particularidade da questão social pode ser enriquecida e adensada na formação profissional e, para isso é importante fornecer subsídios teóricos para essa interlocução. Para além de matérias específicas como Formação Sócio Histórica do Brasil ou Acumulação Capitalista e Desigualdades Sociais, defendemos que a questão agrária deve perpassar o conjunto das matérias, seja como item dos programas ou como interface de diálogo. Para ilustrar essa assertiva, trazemos no final do artigo possíveis interlocuções da questão 


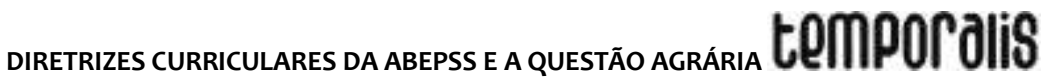

agrária com duas matérias, uma do Núcleo de Fundamentos da Formação Sócio-Histórica da Sociedade Brasileira e outra de Fundamentos Teórico-Metodológicos da Vida Social. ${ }^{1}$

\section{A PERSPECTIVA DE TOTALIDADE, QUESTÃO AGRÁRIA E FORMAÇÃO PROFISSIONAL}

O serviço social brasileiro há décadas vem construindo um projeto profissional numa perspectiva que contrapõe-se ao projeto hegemônico do capital; para isto foi fundamental a apreensão de um referencial teórico capaz de decifrar o processo de dominação imposto pelo capital e, o antagonismo de classes decorrentes dessa forma de organização da produção e reprodução da vida.

Ainda que o serviço social tenha surgido para atender aos interesses do Estado e das classes dominantes, o giro ideopolítico feito pela profissão permitiu a construção de uma direção para o trabalho, a formação e a sua organização política numa perspectiva crítica e alinhada à defesa intransigente de outra sociabilidade. Do ponto de vista teórico foi fundamental a apreensão do amplo legado de Karl Marx e de seus diversos interlocutores, bem como a vasta produção da área dedicada a pensar a realidade do serviço social a partir dessa matriz do pensamento social.

Este processo de apreensão da teoria marxiana encontrou e encontra amplas dificuldades teóricas e metodológicas à medida que é um construto complexo e denso; mas gostaria de destacar as dificuldades políticas, afinal essa teoria traz uma nova percepção da realidade e do mundo que desestabiliza verdades e moralidades historicamente construídas. Ao discutir o método em Marx, Netto (2009) destaca:

\begin{abstract}
No que toca a teoria social de Marx, a questão do método se apresenta como um nó de problemas. E, nesse caso, problemas que não se devem apenas a razões de natureza teórica e/ou filosófica: devem-se igualmente a razões ideopolíticas - na medida em que a teoria social de Marx vincula-se a um projeto revolucionário... [...] Para Marx, a sociedade burguesa é uma totalidade concreta. Não é um 'todo' constituído por partes funcionalmente integradas. Antes, é uma totalidade concreta inclusiva e macroscópica, de máxima complexidade, constituída por totalidades de menor complexidade (NETTO, 2009, p. 668-690).
\end{abstract}

Quando Netto (2009) destaca a diferença entre o todo do positivismo e a totalidade marxiana, é importante atentar-se para fato de que a formação do indivíduo nessa sociabilidade tem nas matrizes teóricas positivistas sua principal fonte, o que desencadeia uma perspectiva fragmentada da realidade social e do trabalho. A dicotomização da realidade e sua apreensão a partir de variáveis, muitas vezes binárias, constroem o principal acervo formativo disponível na sociedade em suas instituições sociais. Ainda que uma série de debates esteja em curso, principalmente a partir do que as correntes pós modernas chamam de crise de paradigmas, a utilização de modelos formais abstratos na análise das relações sociais permanecem não só devido à hegemonia científica desse arsenal teórico/científico em suas diversas expressões, mas também por questões políticas.

\footnotetext{
${ }^{1}$ Por uma questão de espaço, o terceiro núcleo referente aos fundamentos do trabalho profissional está sendo discutido em outro material cuja publicação está em curso.
} 
Guerra (2015) adensa esse debate acrescentando as dificuldades de uma percepção idealista da realidade:

Não é somente o positivismo, com tal perspectiva formal-abstrata, que atua dando suporte a essa percepção, mas o próprio idealismo que faz com que os sujeitos percepcionem a realidade ideal como um designo que lhe foi determinado por um ser superior, destino anteriormente traçado e pronto para ser cumprido, posto que é superior ao sujeito real (GUERRA, 2015, p. 45).

Ainda segundo Guerra (2015) apesar das diferenças entre o racionalismo formal- abstrato e o idealismo, o que ambas tem em comum é seu traço antiontológico, próprio de correntes agnósticas:

Como correntes agnósticas, tanto o idealismo quanto o racionalismo formalabstrato são funcionais a reprodução da ordem social na medida em que desconfiam, descartam, negam, ignoram e, sobretudo desacreditam das possibilidades de desvelamento da realidade para além de sua fenomenalidade, expressões, formas e aparência (GUERRA, 2015, p. 47-48).

Uma característica fundamental da teoria marxiana é exatamente seu caráter radicalmente histórico e ontológico. A partir da análise dialética e dinâmica da realidade, esta é apreendida em seu constante e permanente vir a ser, onde a verdade não é dada a priori, mas reproduz o próprio movimento de constituição da sociabilidade e do ser social. Num primeiro momento, o processo desestabiliza o caminho construído e tido como verdadeiro para a produção do conhecimento; depois impacta a concepção da realidade, a visão de homem e de mundo e exige posicionamento ideopolítico.

A superação do que Karel Kosik (1995) denomina de pseudoconcreticidade exige a percepção da realidade como totalidade:

A totalidade concreta não é um método para captar e exaurir todos os aspectos, caracteres, propriedades, relações e processos da realidade; é a teoria da realidade como totalidade concreta. Se a realidade é entendida como concreticidade, como um todo que possui sua própria estrutura (e que portanto não é caótico), que se desenvolve (e, portanto, não é imutável nem dado de uma vez por todas), que se vai criando (e que portanto, não é um todo perfeito e acabado no seu conjunto e não é mutável apenas em suas partes isoladas, na maneira de ordená-las), de semelhante concepção da realidade decorrem certas conclusões metodológicas que se convertem em orientação heurística e princípio epistemológico para estudo (KOSIK, 1995, p. 44).

Partir do concreto, da realidade efetiva dos homens, da materialidade da vida e de seu constante vir a ser, de seu movimento constituinte é um desafio; identificar seus aspectos essenciais como permanente construção exige esforço teórico/político, pois toda a nossa formação não é dialética e, portanto, não nos subsidia para pensar os fenômenos como complexos sociais moventes cuja essência não é dada a priori. Por outro lado, se apreendermos essa forma de construção do conhecimento será possível superar o claro/escuro de verdade e engano mencionado por Kosik (1995), e seguir na apreensão da realidade como construção histórica e social, ou como destaca Marx:

[...] o concreto é concreto porque é a síntese de muitas determinações, isto é, unidade do diverso. Por isso o concreto aparece no pensamento como processo de síntese, como resultado, não como ponto de partida, ainda que seja o ponto 


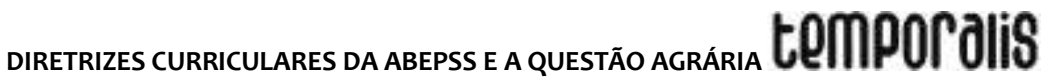

de partida efetivo e, portanto, o ponto de partida também da intuição e da representação (MARX, 1982, p. 14).

Apreender o real numa perspectiva de totalidade é um fundamental para desvendar os determinantes estruturais que construem o antagonismo de classe da sociaedade capitalista e os seus diversos mecanismos de opressão contruídos ou reforçados na atual sociabilidade. Para além das refrações da questão social postas imediatamente no real, a apreensão dos seus elementos fundantes requer um método de apreensão que capte para além da imediaticidade, as mediações que permitem desvendar as particularidades através das quais o real se apresenta como estrutura complexa e movente.

Este é um desafio que está posto a produção do conhecimento como um todo na área das ciências sociais, mas este processo é ainda mais complexo para uma profissão como o serviço social cuja inserção laboral majoritária vai se dar no âmbito da efetivação das políticas públicas e, em condições bastante adversas do ponto de vista dos vínculos empregatícios; a teoria marxiana adentra a profissão como uma concepção de homem/ mundo, mas requer diversas mediações para fornecer subsídios práticos para exercício profissional ou a formação.

Quando a apreensão do real por parte do profssional se dá numa perspectiva de totalidade é possível analisar as políticas públicas e seus determinates a partir de elementos macro estruturais e, com isto, não cair em ilusões idealistas sobre o seu papel na sociaedade capitalista; por outro lado, a apreensão da luta de classe permite recuperar os sujeitos políticos, os embates e as contradições presentes no real como constituintes da questão social, não se limitando, portanto, a mera apreensão de suas refrações.

Daí a intenção desse artigo de construir possibilidades de interlocução da questão agrária, como particularidade da questão social, com as diversas matérias do serviço social, a luz do referencial teórico que orienta o projeto de formação.

\section{A CONSTRUÇÃO DO ATUAL PROJETO DE FORMAÇÃO DO SERVIÇO SOCIAL NO BRASIL.}

O serviço social brasileiro para consolidar a virada teórico-metodológica e ideopolítica promovida na década de 1980 foi desenvolvendo uma séria de ações no âmbito da organização coletiva, do trabalho e da formação. ${ }^{2}$ Uma dessas ações foi a análise e reestruturação da formação profissional com a construção de um novo currículo mínimo em 1982, resultado de um amplo debate político e teórico da profissão no sentido de dar a formação um cariz crítico. A formação é pensada a partir da indissociabilidade entre ensino, pesquisa e extensão e, ainda que estabeleça a divisão entre teoria, método e história do serviço social, na realidade, promove um amplo esforço de pesquisa e reflexão para dar fundamentação ao trabalho profissional, agora identificado como inserido na divisão sócio técnica do trabalho.

Em 1993, na convenção da ABESS deliberou-se pela revisão do currículo mínimo de 1982 de maneira a adensá-lo teoricamente, ainda que na mesma direção e mantendo a

\footnotetext{
${ }^{2}$ A este respeito o serviço social brasileiro possui uma ampla produção a respeito, mas destaco obras seminais deste debate: Netto (1992, 1996) e lamamoto (1999).
}

Temporalis, Brasília (DF), ano 19, n. 37, p. 172-188, jan./jun. 2019. ISSN 2238-1856 
indissociabilidade entre ensino, pesquisa e extensão. Entre 1994 e 1996 procedeu-se a uma profunda avaliação da formação profissional de maneira a levantar os impasses e tensões existentes no processo de ensino/aprendizagem vigente no período. O resultado foi a aprovação na:

XXIX Convenção Nacional da ABESS, em Recife, dezembro de 1995, a Proposta Básica para o Projeto de Formação Profissional, contendo os pressupostos, diretrizes, metas e núcleos de fundamentação do novo desenho curricular. A continuidade deste trabalho coletivo, em 1996, através da realização das oficinas, com a assessoria de um grupo de consultores conduziu a elaboração de um segundo documento intitulado 'Proposta Básica para o Projeto de Formação Profissional: Novos Subsídios para o Debate' (ASSOCIAÇÃO BRASILEIRA DE ENSINO E PESQUISA EM SERVIÇO SOCIAL, 1996, p. 3, grifos do autor).

Ocorre que nesse período estava sendo regulamentado aquilo que tinha sido estabelecido pela recém aprovada Lei de Diretrizes e Bases da Educação- LDB (Lei N 9.394, de 20 de dezembro de 1996) para todos os cursos de níve maior flexibilidade I universitário no país. Em substituição a exigência de currículo mínimo, passava a vigorar diretrizes curriculares, que previam conteúdos que, nas palavras do Governo, permitiriam para a formação profissional nas diversas áreas. Na realidade, a nova LDB viabilizou, do ponto de vista legal, o alinhamento do Estado brasileiro as diretrizes do Banco Mundial para os chamados países em desenvolvimento que previa um amplo processo de mercantilização do ensino superior. ${ }^{3}$

A partir de então, a ABESS se mobiliza politicamente e propõe junto ao Ministério da Educação que o documento recém aprovado possa assumir como diretrizes curriculares para o curso de serviço social. Para isso, o documento original passa por um processo de adequação as normativas legais feita por uma comissão de especialistas que finaliza o documento em 1999 e, a entidade agora denominada de ABEPSS, o apresenta ao MEC.

Ainda que esse protagonismo seja digno de nota - afinal foi o curso que evidenciou maior nível de organização e democracia interna,$-{ }^{4}$ o MEC ao aprovar as diretrizes curriculares para os cursos de serviço social, embora tenha assumido em linhas gerais o formato proposto pela ABESS/ABEPSS estabelecendo que o processo de formação se daria a partir dos três núcleos de fundamentação, ele descaracteriza a proposta como um todo a medida que retira o seu direcionamento ético político. Motta (2007) afirma que as mudanças foram tão significativas que descaracterizaram a proposta apresentada pela ABEPSS: "[...] as supressões incidiram tanto no perfil do profissional como no elenco das competências e na total exclusão das matérias e ementas elaboradas pela Comissão de Especialistas, em 1999" (MOTA, 2007, p. 60).

Ainda que o MEC tenha aprovado suas diretrizes deturpando a proposta original da ABEPSS, a categoria a e entidade em específico, seguiram no debate sobre a formação tendo como referência o documento Diretrizes Gerais para os Cursos de Serviço Social construído pela

\footnotetext{
${ }^{3} \mathrm{O}$ debate sobre o ensino superior é tema frequente na revista Temporalis. A esse respeito CF: Temporalis. Ano 15, n. 3; Temporalis. Ano 10, n. 19.

${ }^{4} \mathrm{O}$ curso de serviço social foi o único que apresentou ao Ministério da Educação uma proposta de diretrizes resultado de uma amplo processo de discussão das unidades de ensino articulado pela Associação Brasileira de Escolas de Serviço Social (ABESS), hoje ABEPSS.
}

Temporalis, Brasília (DF), ano 19, n. 37, p. 172-188, jan./jun. 2019. ISSN 2238-1856 
ABEPSS com base no Currículo Mínimo aprovado em Assembleia Geral Extraordinária da entidade em 8 de novembro de 1996.

O documento traz uma proposta formativa cujos pressupostos apontam para uma perspectiva crítica: a questão social, como embate da relação capital/ trabalho, é identificada como o fundamento do trabalho profissional; o serviço social é reconhecido como uma profissão inserida na divisão sócio técnica do trabalho; e o trabalho como eixo fundante da sociabilidade (ASSOCIAÇÃO BRASILEIRA DE ENSINO E PESQUISA EM SERVIÇO SOCIAL, 1996, p. 6-7).

A proposta é que, no processo formativo, o estudante tenha condições desenvolver capacitação teórico-metodológica, ético-político e técnico-operativa a partir de uma nova lógica curricular assentada em três núcleos de fundamentação: Núcleo de Fundamentos Teórico-Metodológicos da Vida Social, Núcleo de Fundamentos da Formação SócioHistórica da Sociedade Brasileira e o Núcleo de Fundamentos do Trabalho Profissional. Estes núcleos funcionam como eixos articuladores da formação e se desdobram em áreas do conhecimento, as quais pedagogicamente são expressas no conjunto das matérias que se diversificam nos diferentes componentes curriculares (disciplinas, seminários temáticos, oficinas/laboratórios, atividades complementares e outros componentes curriculares).

Os núcleos não são subsequentes ou fragmentadores do conhecimento, aliás, pelo contrário: o documento destaca e importância de seu tratamento articulado no processo formativo posto que remetem

[...] a um conjunto de conhecimentos indissociáveis para a apreensão da gênese,
das manifestações e do enfrentamento da questão social, eixo fundante da
profissão e articulador dos conteúdos da formação profissional. Portanto, os
Núcleos mencionados não são autônomos nem subsequentes, expressando, ao
contrário, níveis diferenciados de apreensão da realidade social e profissional,
subsidiando a intervenção do Serviço Social (ASSOCIAÇÃO BRASILEIRA DE
ENSINO E PESQUISA EM SERVIÇO SOCIAL, 1996, p. 9).

As disciplinas que compõem as diversas matérias dos três núcleos podem estar em diferentes combinações na grade curricular de um curso, porém devem compor um conjunto de conhecimentos sobre o ser social, a realidade brasileira e o trabalho profissional para que o futuro assistente social tenha uma percepção crítica da sociedade na qual está inserido e dos rebatimentos desse contexto nos diversos espaços sócio ocupacionais e no trabalho profissional.

Esse estudo procura adensar o debate sobre a presença da questão agrária como particularidade da questão social à medida que esta expressa os embates de classe decorrentes dos modelos de produção agrária e agrícola vigentes em nosso país; e este é um elemento fundamental para o entendimento da gênese da questão social brasileira e de seus pilares de exploração e opressão.

A tese que nos orienta é que as diretrizes curriculares da ABEPSS permitem a discussão da questão agrária como uma particularidade da questão social, fundamento do trabalho profissional. A razão de tal assertiva é que os embates da relação capital trabalho, constituintes da questão social, se expressam no campo e na cidade, por processos que

Temporalis, Brasília (DF), ano 19, n. 37, p. 172-188, jan./jun. 2019. ISSN 2238-1856 
envolvem o desenvolvimento produtivo agrário e urbano; portanto, a questão social é permeada pelas contradições desse processo que quando são decoorentes do agrário, constituem se como particularidades que dão a ela uma dada conformação com elementos específicos e problemáticas diferenciadas. Porém, como nem sempre o debate sobre a particularidade do rural se faz presente na literatura profissional; a discussão sobre o tema, quando acontece, fica restrita a algumas disciplinas, principalmente aquelas que analisam a realidade brasileira ou os fundamentos da questão social. Defende-se aqui que a apreensão da questão agrária pode, de fato, não estar sendo trabalhada em algumas disciplinas, mas deveria estar presente em diversas interlocuções que compõem as matérias dos três núcleos. Ou seja: a questão agrária já compõe o conteúdo previsto para as matérias, porém, para que de fato, ela possa estar sendo discutida e trabalhada nos temas da formação profissional, é preciso que o docente tenha uma perspectiva de totalidade e que perceba a transversalidade do debate sobre o rural/urbano nos elementos que compõem a realidade social. Para isso ele terá que apreender os complexos sociais e suas mediações numa perspectiva dialética e de totalidade.

Ainda que a abordagem da questão agrária em disciplinas específicas possa garantir acesso a determinados conteúdos específicos que tratam das particularidades que constituem o urbano, o rural e o ambiental, o mais adequado é que estes conteúdos se façam presentes nos três eixos de formação. Embora seja fundamental entender a questão agrária no processo de formação da sociedade brasileira, o assistente social precisa saber, também, os rebatimentos desse modelo produtivo voltado para o agronegócio no seu cotidiano profissional, nas políticas e até em seus fundamentos primeiros que explicam a atual disputa da natureza como um bem privado.

Se a questão agrária é parte constitutiva da questão social e se faz presente a partir das mediações trazidas pelas relações capitalistas no campo, o/a profissional para ter perspectiva de totalidade, precisa apreender as determinações do rural que perpassam a questão social pois, é dela que decorrem refrações como: adoecimento em massa da população devido a contaminação dos alimentos por agrotóxicos, êxodo rural e permanência de uma das estruturas agrárias mais concentradas do mundo, trabalho precarizado no campo e em municípios de pequenos porte, cerco as terras indígenas e Quilombolas e desqualificação das culturas dos povos tradicionais, conflitos agrários e a presença de mais de 100 movimentos sociais rurais no Brasil. Ou seja: para entender a questão social é preciso identificar as particularidades do rural que compõem a luta de classes e a configuração da terra e do trabalho neste país.

O debate a seguir não pretende direcionar o lugar da questão agrária na formação profissional, apenas contribuir para dar visibilidade às possibilidades que apreendemos para essa interlocução nos conteúdos ilustrando com duas matérias, uma de cada Núcleo, mais especificamente que tratam dos fundamentos do ser social e o da realidade brasileira; uma contribuição modesta, mas que está sendo feita a partir da experiência de vários anos de pesquisa sobre a questão agrária e, do mesmo tempo de debate sobre os fundamentos do trabalho profissional. O terceiro núcleo não foi trabalhado nesse artigo por uma questão de espaço, conforme já mencionado, pois devido a especificidade de trabalhar a realidade profissional exigiria um conjunto de mediações diferenciadas e com exemplos 


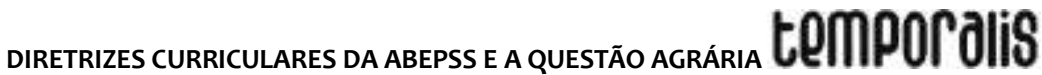

concretos como o fez Sant'Ana $(2012,2014){ }^{5}$ para evidenciar a relação direta entre diversos espaços sócio ocupacionais e a questão agrária como principal elemento constituinte da questão social em determinados territórios.

As matérias foram escolhidas aleatoriamente, ${ }^{6}$ depois de retirada aquelas de interlocução obvia como Formação Sócio Histórica do Brasil e Acumulação Capitalista e Desigualdades Sociais. Para facilitar a apresentação, iremos apresentar a ementa da matéria a e partir daí tecer nossa análise.

\section{NÚCLEO DE FUNDAMENTOS TEÓRICO-METODOLÓGICOS DA VIDA SOCIAL Matéria: Economia política}

\begin{abstract}
Ementa: A constituição da economia política como campo científico. O Liberalismo, o Keynesianismo, o Neoliberalismo e a Crítica Marxista da Economia Política. Os projetos societários gestados nos modos de organização das relações econômico-políticas de produção e reprodução. As mudanças contemporâneas no padrão de acumulação e suas expressões na economia brasileira e internacional (ASSOCIAÇÃO BRASILEIRA DE ENSINO E PESQUISA EM SERVIÇO SOCIAL, 1996, p.16).
\end{abstract}

No debate sobre os projetos societários, a interface agrária do projeto do capital é fundamental. Em âmbito rural, o capital promove um modelo de produção voltado para o mercado de commodities, cuja base de sustentação da atividade agrícola é a produção em larga escala de um único produto, via de regra, utilizando se de trabalho assalariado, insumos químicos e mecanização pesada que compacta o solo; os efeitos nocivos desse modelo de agricultura sobre meio ambiente e a sociabilidade são mediações fundamentais para pensar a produção e a reprodução atuais.

Mitidiero Júnior (2016) apoiando-se em Mészáros (2002) argumenta que a perspectiva expansionista do capital e a necessidade de superação de uma crise profunda, pois estrutural, envolve novas estratégias de acumulação que Harvey (2014) denomina de "acumulação por espoliação". Ainda que esta tenha vários elementos comuns com a acumulação primitiva do capital, novos construtos são aperfeiçoados de maneira a manter o atual sistema sóciometabólico em permanente expansão. Mitidiero Junior (2016) argumenta sobre a importância da apropriação da natureza como bem finito, o que pode trazer para o capital o controle sobre os territórios de maneira a assegurar poder e renda de monopólio e, o desenho de geopolíticas cada vez mais controladas pelos países imperialistas.

\footnotetext{
${ }^{5}$ Sant'Ana (2012), constatou que as assitentes sociais de município s de pequeno porte da região nordeste do estado de São paulo conseguiam apreender que o principal usuário da assistencia sociao eram trabalhadores ou ex trabalhadores rurais do setor canavieiro mas não tinham a quantificação desse dado; em 2014, autora realiza um pesquisa específica para precisar esta informação e contata que de fato a percepção dos assistentes sociais era correta: os trabalhadores e ex trabalhadores em municípios de até 20 mil habitantes eram 70 \% dos usuários dos Centros de Referência de Assistencia Social. A partir destas informações foi possível evidenciar como a questão agrária envolvendo a cadeia produtiva do agronegócio era uma determinação fundamental na constituição da questão social nos pequenos muncípios da região.

${ }^{6} \mathrm{Na}$ realidade este trabalho é resultado de estágio pós doutoral realizado no Programa de Pós-Graduação em Serviço Social da UFRJ e, no relatório final havia a discussão da interlocução da questão agrária com todas as matérias de cada Núcleo, mas devido aos limites de espaço, optou-se por selecionar apenas uma por Núcleo.
}

Temporalis, Brasília (DF), ano 19, n. 37, p. 172-188, jan./jun. 2019. ISSN 2238-1856 


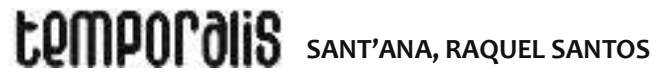

Entender essas relações como um projeto de sociedade construído pelo capital possibilita ao assistente social, no trabalho sócio educativo: ter conteúdo para discutir os modelos de educação ambiental propostos pelas políticas públicas privadas ou estatais; apreender as questões de disputa dos territórios urbanos ou rurais a partir de mediações muito mais ampliadas do que as orientações sistêmicas das políticas sociais; e enfocar temas cujos rebatimentos aparecem no cotidiano das famílias como se fossem desconectados das relações estruturantes dessa sociabilidade, mas que são constituintes desse modo de vida.

Um exemplo dessa perspectiva alargada é o debate sobre a fome e a criminalização da pobreza cada vez mais presente na sociabilidade. Estes temas são tratados sempre de forma superficial ou mesmo de maneira a esconder seus verdadeiros determinantes como a mercantilização do alimento pelos grandes conglomerados agroindustriais e os riscos desse processo para a soberania alimentar dos povos; a concentração da terra e sua importância na configuração da pobreza urbana e rural; o modelo de agricultura que expulsa os camponeses de seus territórios e que produz grandes monoculturas vinculadas ao mercado de commodities. Estes são exemplos dos processos violentos desencadeados pelo modelo de agricultura vigente na sociedade do capital e que podem constituir em interlocuções ampliadas para o debate sobre a questão agrária na formação profissional.

A lógica do capital ao se espraiar por todos os interstícios da vida social se alastra nos diversos territórios dando configurações específicas para a forma de ocupação do solo urbano e rural em todos os continentes e estabelecendo, inclusive, uma determinada configuração para as relações entre os países.

No Brasil os impactos da agricultura capitalista trazem graves implicações para os povos tradicionais, camponeses, quilombolas, ribeirinhos, pescadores e outros sujeitos que compõem a diversidade do provo brasileiro, mas afetam também os moradores da cidade, pois determinam o preço, a composição, a disponibilidade dos alimentos em geral. Cada vez mais resíduos tóxicos e substancias impróprias para o consumo humano são encontrados nos alimentos, pois nossa alimentação se tornou uma mercadoria como outra qualquer; a padronização alimentar em curso tem provocado cada vez maior empobrecimento cultural e nutricional da população em geral.

As mudanças contemporâneas no padrão de acumulação passam pelo debate sobre o mercado de commodities, pois os principais grãos que alimentam os seres humanos passam a ser geneticamente modificados e, portanto, passam a ser patrimônio de pouquíssimas empresas privadas. Uma das mais contundentes expressões da acumulação capitalista é a persistência da fome em âmbito planetário quando a disponibilidade de alimentos é suficiente para alimentar o dobro da população terrestre. Como afirma Ziegler (2013):

A destruição anual de dezenas de milhões de homens, mulheres e crianças pela fome constitui o escândalo de nosso século. A cada cinco segundos, morre uma criança de menos de dez anos. Em um planeta que, no entanto, transborda de riquezas [...] No seu estado atual, a agricultura mundial poderia alimentar sem problemas 12 bilhões de seres humanos - vale dizer, quase duas vezes a população mundial atual. Quanto a isto, pois, não existe nenhuma fatalidade. Uma criança que morre de fome é uma criança assassinada (ZIEGLER, 2013, p. 21). 


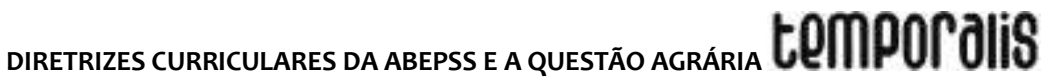

Esse debate deve compor a formação profissional de maneira a evidenciar que na agricultura existem, também, diferentes projetos em disputa. O projeto hegemônico indica como única possibilidade para a eliminação da fome e da miséria a produção monocultural em larga escala com utilização intensiva de agrotóxico; os movimentos sociais e os sujeitos que disputam o projeto de produção para o campo se contrapõem com a pluriatividade camponesa, com a agroecologia, enfim com modelos produtivos que podem ser alternativas viáveis do ponto de vista ambiental, social e econômico.

É evidente que não cabe apenas a esta matéria trazer o conjunto de problemáticas que evidenciam a questão agrária como componente da questão social, no entanto quando seus conteúdos forem abordar os projetos societários, o debate sobre modelo de desenvolvimento agrário deve perpassar os temas a serem discutidos; quando se discute a geopolítica mundial e sua configuração há de se mencionar os recursos naturais e sua disponibilização em nível planetário; quando se discute mercado de trabalho e exploração, há-de-se destacar que esse processo ocorre com diferentes particularidades incluindo o campo e a cidade. A abordagem destes temas irá proporcionar ao estudante ampliar o seu olhar não se limitando às problemáticas urbanas.

\section{NÚCLEO DE FUNDAMENTOS DA FORMAÇÃO SÓCIO-HISTÓRICA DA SOCIEDADE BRASILEIRA}

Matéria: Política Social

Ementa: As teorias explicativas da constituição e desenvolvimento das políticas sociais. A questão social e desenvolvimento do sistema brasileiro de proteção social. Formulação e gestão das políticas sociais. A constituição e gestão do fundo público. O papel dos sujeitos políticos na formulação das Políticas Sociais Públicas e Privadas. As políticas setoriais e a legislação social. A análise comparada de políticas sociais. O papel das políticas sociais na constituição da esfera pública e o significado do debate público e privado. As novas formas de regulação social e as transformações no mundo do trabalho (ASSOCIAÇÃO BRASILEIRA DE ENSINO E PESQUISA EM SERVIÇO SOCIAL, 1996, p. 17).

O enfoque sobre as políticas públicas e as formas de gestão são fundamentais ao serviço social não só pela sua inserção laboral, via de regra, vinculado a elas, mas também, no diálogo com o fundamento da questão social e, acrescento aqui, sua particularidade com a realidade agrária. Numa sociedade capitalista e na realidade brasileira em específico, entender o papel do Estado e das políticas públicas, especialmente as políticas sociais, é condição para fortalecer o profissional no sentido de lutar pela qualidade do serviço, pela ampliação dos acessos, porém sem iludir-se no sentido de que por essa via ele poderá alterar os elementos estruturais que fundamentam a questão social.

O debate sobre o sistema de proteção social é fundamental para dar visibilidade a histórica violação dos direitos dos trabalhadores, em especial dos trabalhadores rurais. Grande parte dos idosos que não conseguem comprovar vínculo empregatício durante sua vida laboral é proveniente das áreas rurais, ${ }^{7}$ o que evidencia a necessidade de alguns benefícios

\footnotetext{
7 Masson (2011) em seu estudo sobre os usuários da política de assistências social evidencia o vínculo entre a informalidade do trabalho rural nas colheitas de café e o Benefício de Prestação Continuada destinado aos idosos na região de Altinópolis (SP).
}

Temporalis, Brasília (DF), ano 19, n. 37, p. 172-188, jan./jun. 2019. ISSN 2238-1856 
criados pela política pública nos sentido de assegurar minimamente as condições de sobrevivência desse segmento, como é o caso do Benefício de Prestação Continuada (BPC) previsto pela Lei Orgânica da Assistência Social (Lei n 8742, de 07 dezembro de 1993). ${ }^{8}$

Também no âmbito da política pública, o debate sobre a reforma agrária é fundamental. Os assentamentos rurais requerem uma série de políticas sociais que, via de regra, são efetivadas com a participação dos assistentes sociais e os profissionais podem se comprometer com uma perspectiva diferenciada no atendimento ou não; o mesmo ocorre em territórios quilombolas, indígenas e de outras ${ }^{9}$ comunidades tradicionais. A maneira como o profissional irá se aproximar desses territórios e das demandas dos sujeitos neles inseridos, está diretamente relacionada aos seus subsídios teóricos para a compreensão da luta pela terra no Brasil, dos movimentos sociais como sujeitos políticos, da diversidade cultural e étnica e até do urbanocentrismo que orienta as políticas sociais de maneira geral - temas estes que no processo de formação outras matérias irão trabalhar com mais ênfase.

Os elementos acima mencionados permeiam a discussão do rural, porém tão importante quanto essa apreensão é identificar a questão agrária nas diversas políticas setoriais, em especial na de assistência social. ${ }^{10}$

$\mathrm{Na}$ assistência social é importante considerar três aspectos: 1- a tentativa de fazer da política de reforma agrária uma política de assistência; 2- o debate sobre a relação entre assistência social e a política nacional de segurança alimentar e nutricional; 3- a relação entre política de assistência e precarização do trabalho.

1- Os governos do Partido dos Trabalhadores (Lula: 2003 a 2010; Dilma 2011 a 2016), atendendo as orientações do Banco Mundial, reduziram o escopo da política de reforma agrária a uma política social, descaracterizando seu real significado de política de desenvolvimento destinada a mudar a configuração da estrutura fundiária e, promover a democratização do acesso a terra no Brasil.

Isso colocou diversas dificuldades às comunidades assentadas, mas em especial uma que é fundamental: ao invés de investir em políticas voltadas para a reprodução econômica da família assentada garantindo assim a sua autonomia como unidade produtora familiar, o governo acabou construindo bolsões de pobreza onde as comunidades acessavam mais aos programas focalizados de transferência de renda do que, de fato, créditos voltados para o custeio e fomento das atividades produtivas. Isso gerou dificuldades para as comunidades assentadas e colocou a democratização do acesso a terra fora do debate político, deixando em seu lugar apenas o questionamento da viabilidade da reforma agrária

\footnotetext{
${ }^{8}$ A esse respeito CF: Brasil (1993).

${ }^{9}$ É preciso destacar que o presidente Bolsonaro está propondo um ampla reforma do sistema previdenciário brasileiros com alterações que afetam o conjunto da classe trabalhadora, mas especificamente com relação ao BPC propõe a redução do valor atual de 998 para 400 reais

${ }^{10}$ Interessante seria discutir também a inter-relação com a Política da Saúde, mas por uma questão de espaço, não será possível. Daremos então, apenas um exemplo: quando o foco é saúde do trabalhador numa região monocultora de cana de açúcar a relação é direta, pois os acidentes de trabalho estarão vinculados a essa cadeia produtiva como constataram Lourenço (2013), Sant'ana e Carmo (2010); mas quando o foco é a saúde da população e o aumento dos índices de canceres decorrentes desse jeito de viver e alimentar-se, o vínculo aparece mediado por outros elementos relacionados a questão agrária.
} 


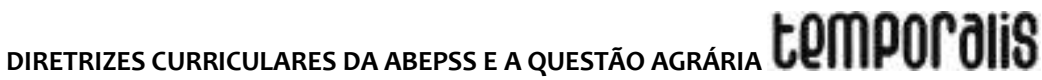

como política pública de desenvolvimento. No governo Temer (2016-2018) - que assumiu por meio de um golpe parlamentar institucional - essas políticas sociais foram declinando. No atual Governo de Jair Bolsonaro os retrocessos são evidentes: a suspensão da demarcação de terras indígenas e quilombolas, a suspensão da política pública de reforma agrária, a extinção do Conselho Nacional de Segurança Alimentar e Nutricional a partir da revogação de todos os artigos Lei orgânica de Segurança alimentar e Nutricional (LOSAN/2006) que tratavam do Conselho e, inúmeras outras medidas que violam direitos conquistados como o Programa Nacional de Educação em Reforma Agrária (PRONERA).

O/A assistente social precisa conhecer o debate sobre a realidade agrária brasileira para poder fazer a defesa da democratização do acesso da terra, da legitimidade dos movimentos sociais e de políticas públicas que respeitem o universo cultural e social das diversas populações do campo em sua diversidade. Isto significa que ao longo da formação ele terá que acessar que o índice de Gini, que mede concentração fundiária, no Brasil nunca foi menor que 0.8 , ou seja, quase concentração absoluta; que está na Constituição Federal Brasileira a exigência que terra cumpra a função social; que a forma como se conduziu o acesso a terra no Brasil contribuiu de maneira decisiva para a dívida histórica para com a população negra, e portanto, hoje traz a necessidade das políticas afirmativas e das cotas raciais e sociais. É evidente que as disciplinas de indicadores sociais, legislação social, ética, formação sócio histórica da sociedade brasileira irão ter interface com o debate, mas isso não exime a política social de trabalhar também a política de reforma agrária e suas particularidades como componente das políticas públicas.

2- A outra interface da política de assistência social com a questão agrária (e política de Reforma Agrária) é por meio da política Nacional de Segurança alimentar e nutricional. O atual governo está promovendo um desmonte nesta área, mas é importante conhecer para realizar a defesa de alguns direitos conquistados. O Programa de Aquisição de Alimentos (PAA) e o Programa da Merenda Escolar preveem a compra de alimentos da agricultura familiar e dos assentamentos para abastecer as instituições e escolas em âmbito municipal. A presença nos Conselhos alimentares e nutricionais nas três esferas de governo (federal, ${ }^{11}$ estaduais e municipais) visando assegurar que os alimentos ofertados nas escolas e creches de todos os municípios brasileiros possam assegurar qualidade nutricional adequada é fundamental; esse é um espaço ainda pouco debatido no âmbito do serviço social, porém com uma interface direta sobre a questão social e que, se o profissional tiver o acúmulo sobre a particularidade que compõe a questão agrária, com certeza estará mais qualificado para essa participação e para o debate político que essa inserção requer, como por exemplo: o que significa fortalecer a agricultura camponesa? Que tipo de alimento está sendo ofertado por essa agricultura? O que são agrotóxicos? O que é agroecologia? Debates que podem contribuir para um trabalho educativo que contemple para além dos temas sócio educativos previstos nas políticas, outros como: direito a terra, alimentação saudável, transgenia e etc.. A responsabilidade para essa apreensão é de várias matérias, mas chegar às diferentes disciplinas da matéria de política social é fundamental.

3- O outro aspecto a ser considerado diz respeito à interface entre precarização do trabalho e a demanda por assistência social por parte da população mais pauperizada. $\mathrm{O}$

\footnotetext{
${ }^{11}$ Este conforme mencionado foi extinto pela medida provisória $n^{\circ} 870$ de $1^{\circ}$ de janeiro de 2019.
} 
agronegócio não absorve mais que 25 \% da força de trabalho rural, e ainda assim o faz de forma precarizada. Um exemplo ilustra bem a assertiva. Sant'Ana $(2012,2014)$ em pesquisas realizadas nos últimos 10 anos na região de Franca e Ribeirão Preto, municípios do interior do estado de São Paulo, evidencia que o avanço tecnológico do agronegócio não se estende as relações de trabalho. Os trabalhadores rurais vinculados ao setor sucroalcoleiro eram contratados em condições extremamente precarizadas e mais, quando o trabalhador evidenciava sinais de adoecimento, era imediatamente descartado. Como o trabalho no corte da cana de açúcar era muito árduo e desgastante, aos 40 anos os trabalhadores já não eram mais contratados. Nos municípios de pequeno porte da região, esse público, via de regra, se torna o principal usuário da política social. Um homem que ainda faz parte da população economicamente ativa, pois tem cerca de 40 anos, mas que foi descartado pela agroindústria e que vive num município cuja área rural é ocupada pela monocultura da cana de açúcar, não encontra outras opções de trabalho e, fica a mercê da parca assistência viabilizada pela política.

A identificação das condições reais vivenciadas por esses sujeitos e das características das atividades do agronegócio, exige que a análise ultrapasse o âmbito imediato da realidade, pois nessa esfera, a atividade da agroindústria aparece como único recurso de emprego para a população que trabalha em área rural. Na região de Ribeirão Preto, com a mecanização, que atualmente atinge mais de $90 \%$ da colheita, esse quadro se agravou ainda mais e só não ganhou contornos ainda mais acentuados, pois grande parte da força de trabalho utilizada nessa cultura era migrante e deixou de vir para a região.

Discutir assistência social, portanto, pressupõe a análise das condições de trabalho na realidade onde o/a assistente social está atuando e, uma das áreas mais precarizadas é exatamente a área rural. Em outras cadeias produtivas do agronegócio, o trabalho assalariado precarizado parece ser a regra, como foi constatado por Sant'Ana, Lourenço e Carmo (2017) e Sant'Ana; Gomes e Campos (2016).

\section{CONSIDERAÇÕES FINAIS}

Este artigo traz a reflexão sobre a questão agrária na formação em serviço social a partir do referencial marxiano, ou seja, a parti do principal constructo teórico que fundamenta a atual direção ético política da profissão.

Para pensar o mundo, o trabalho e a formação a partir deste referencial é preciso desenvolver capacitação teórico metodológica para apreender os fenômenos numa perspectiva de totalidade onde os conjunto das relações instituídas possam ser identificadas em sua complexidade e movimento.

A qualidade da formação em serviço social no atual contexto encontra-se amplamente ameaçada pela conjuntura política atual e pelo profundo processo de precarização da formação que vem ocorrendo há vários anos e que se constituí numa ameaça permanente a atual direção crítica da profissão.

Daí a intenção desse artigo no sentido de contribuir com o aprofundamento do debate sobre a questão social a partir de sua particularidade rural. 


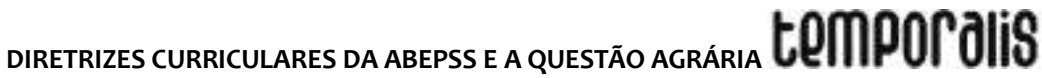

Conforme mencionado no corpo do texto, entendemos que as diretrizes curriculares da ABEPSS, principal documento orientador da formação profissional das escolas alinhadas à atual direção crítica da profissão, pressupõe a perspectiva de totalidade no trato da questão social e, portanto, inclui as diversas particularidades que a compõem incluindo os embates advindos das relações capitalistas no campo, as quais convencionamos chamar de questão agrária. Porém, a perspectiva urbanocêntrica presente na sociabilidade também se manifesta no âmbito da ciência de uma maneira geral e, traz incidências inclusive na formação em serviço social, o que faz com que a problemática rural, muitas vezes, permaneça inviabilizada ou sequer identificada como um componente estruturante da questão social.

O intuito foi de contribuir fornecendo subsídios para que a apreensão da particularidade da realidade rural no conjunto das matérias e disciplinas, mas devido a limitação de espaço, procuramos focar nos dois Núcleos de Fundamentação presentes nas Diretrizes que tratam da formação do ser social e da realidade brasileira, e nestes elencar uma matéria para esta interlocução. Na realidade um pequeno ensaio, pois o detalhamento exigiria um leque maior de mediações a serem construídas para dar visibilidade ao conjunto de elementos presentes no debate dessa temática.

A ideia é que o debate sobre a realidade agrária deve perpassar os três núcleos de fundamentação e nas diferentes matérias, as temáticas discutidas precisam incluir a interface do rural. Ou seja, para discutir trabalho, pesquisa, fundamentos, enfim, os conteúdos das diversas disciplinas podemos e devemos incluir as particularidades da questão social que se expressam como questão agrária.

\section{REFERÊNCIAS}

ASSOCIAÇÃO BRASILEIRA DE ENSINO E PESQUISA EM SERVIÇO SOCIAL. Diretrizes Gerais para o curso de serviço social (com base no currículo mínimo aprovado em Assembléia Geral Extraordinária de 8 de novembro de a1996. Rio de Janeiro, novembro de 2006. Disponível em: http://www.abepss.org.br/files/Lei_de_Diretrizes_Curriculares_1996.pdf. Acesso em: 8 dez. 2015.

BRASIL. Lei Orgânica da Assistência Social. Brasília (DF), 1993. Disponível: http://www.planalto.gov.br/ccivil_03/leis/L8742compilado.htm. Acesso em: 7 dez. 2016.

GUERRA, I. Sobre a possibilidade histórica do projeto ético-político profissional: a apreciação crítica que se faz necessária. In: FORTI, V., GUERRA,I. Projeto Ético Político do Serviço Social: contribuições à sua crítica. Rio de Janeiro: Lumen Juris, 2015.

HAVEY, D. O novo imperialismo. 8. Ed. São Paulo: Edições Loyola, 2014.

IAMAMOTO, V. M. O Serviço Social na contemporaneidade: trabalho e formação profissional. 22. ed. São Paulo: Cortez, 1999.

KOSIK, K. Dialética do concreto. Rio de Janeiro: Paz e Terra, 1995. 
LOURENÇO. E. A. Alienação e Agravos à Saúde dos Trabalhadores no Setor Sucroenergético. In: NAVARRO, V. L., LOURENÇO,E. A.(orgs) O Avesso do Trabalho III: saúde do trabalhador e questões contemporâneas. São Paulo: Outras Expressões, 2013. 494p.

LOURENÇo, E. A. S.; SANT'ANA, R. S.; CARMO, O. A. Precarização e degradação do trabalho no setor canavieiro e citrícola no interior do Estado de São Paulo. In: NAVARRO, V. L.; LOURENÇO, E. A. (Orgs.). O avesso do trabalho IV: precarização e adoecimento no mundo do trabalho. São Paulo: Outras Edições, 2017.

MARX, K. Para a crítica da Economia política: salário, preço e lucro/o rendimento e suas fontes. São Paulo: Abril Cultural, 1982. (Coleção os Economistas).

MASSON, G. A. Um estudo do Benefício de Prestação Continuada no município de Altinópolis: o impacto na vida de seus beneficiários. Orientadora: Profa ${ }^{a}$. Dra ${ }^{a}$. Patrícia Soraya Mustafa. 2011. 176 f. Dissertação (Mestrado em Serviço Social)-Universidade Estadual Paulista “Júlio de Mesquita Filho”, Franca, 2011.

MÉSZÁROS, I. Para Além do Capital: rumo a uma teoria da transição. São Paulo: Boitempo Editorial, 2006.

MÉSZÁROS, I. Para Além do Capital: rumo a uma teoria da transição. São Paulo: Boitempo Editorial, 2002.

MITIDIERO JÚNIOR, M. A. Crise do capital global, natureza e agronegócio. In: Ramos Filho, E.S.; MITIDIERO, J. M. A.; SANTOS, L. R. S (Orgs). Questão agrária e conflitos territoriais. São Paulo: Outras Expressões, 2016.

MOTA, A. E. Trabalho e Serviço Social: considerações sobre o conteúdo dos componentes curriculares. Temporalis, Brasília (DF): Abepss, ano 7, n. 14, jul./dez. 2007.

NETTO, J. P.Introdução ao método na teoria social. Direitos sociais e competências profissionais. Conselho Federal de Serviço Social e Associação Brasileira de Ensino e Pesquisa em Serviço Social. Brasília: CFESS/ABEPSS, 2009, p. 667-700.

NETTO, J. P. Capitalismo Monopolista e Serviço Social. São Paulo: Cortez, 1996.

NETTO, J. P. Ditadura e Serviço Social: uma análise do serviço social pós 64. São Paulo: Cortez, 1992.

SANT'ANA, R. S.Trabalho e modelo de desenvolvimento: a realidade rural e as expressões da questão social. Serviço Social e Sociedade, São Paulo, n. 120, p. 723-745, out./dez. 2014. Disponível em: http://www.scielo.br/pdf/sssoc/n120/08.pdf. Acesso em: 7 dez. 2016.

SANT'ANA, R. S. Trabalho bruto no canavial: questão agrária, assistência e Serviço Social. São Paulo: Cortez, 2012. 


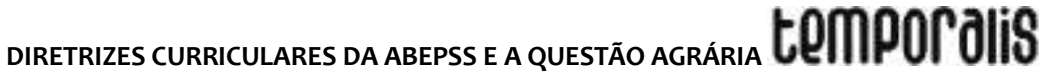

SANT'ANA, R. S.; CARMO. As Condições de Trabalho no setor Sucroalcoleiro. In: LOURENÇO, E.A; NAVARRO,V.; SANT'ANA, R.S.; BERTANI, I; SILVA, J. F. S. O Avesso ao Trabalho II. São Paulo: Expressão Popular, 2010. p.343-66.

SANT'ANA, R. S; GOMES, L; CAMPOS, J. C. O trabalho assalariado nos milharais da Monsanto: um estudo sobre as atividades da região de Franca, SP. In: ENCONTRO NACIONAL DE PESQUISADORES EM SERVIÇO SOCIAL, 15., 2016, Ribeirão Preto. [Anais...]. Ribeirão Preto, 2016.

ZIEGLER, J. Destruição em massa: geopolítica da fome. São Paulo: Cortez, 2013.

\footnotetext{
Raquel Santos Sant'Ana

Doutora e Livre docente em Serviço Social, professora adjunta da Faculdade de Ciências Humanas e Sociais de Franca (UNESP). Leciona Fundamentos Teóricos Metodológicos do Serviço Social para graduação. Discute a relação entre: questão agrária e serviço social. É uma das coordenadoras do Núcleo Agrário Terra e Raiz (NATRA), grupo interdisciplinar de extensão universitária que atua junto aos movimentos sociais da região de Franca e Ribeirão Preto (SP) e membro do Grupo de Pesquisa Teoria Social de Marx e Serviço Social.
} 